\title{
The language and values of genetics: invited editorial on "letter to the editor: time to update the language of genetics from the 19th to the twenty-first century. A response to Schmidtke and Cornel" $\mid$ by Small, Mason and Wright) (DOI: 10.1007/s12687-020-00467-3).
}

Angus Clarke ${ }^{1}$

Published online: 23 June 2020

(C) Springer-Verlag GmbH Germany, part of Springer Nature 2020

The Letter to the Editor of Small et al. (2020) is timely, reminding us that language plays such a key role in displaying our values - making them apparent - even when they are not explicitly the topic of conversation. It is an elegant response to the stimulating grit provided by Schmidtke and Cornel (2020) and refers to the experiences of the authors in relation to their involvement mediating between families who participated in the Born in Bradford project and the findings of the much larger, meta-study reported by Clark et al. (2019). The authors' team, in frequent contact with the local community, anticipates that the findings of the larger project might raise concerns not only intrinsically, because of what has been found and how it has been interpreted, but additionally from the language in which the findings are expressed. They select three words - "inbreeding", "mating" and "pedigree" - to exemplify words that might cause offence when applied to the human context.

These observations are important and warrant further reflection and discussion. In particular, we need to recognize that there are several distinct elements among the objections that may be made to such scientific reports: we are not dealing with a single irritant but a cluster of provocations.

The word "pedigree" has its own pedigree, of course, and used to be applied to humans - principally the nobility - before its use broadened out to include animals, ideas, and even the etymology of words. Its application to humans has lost favour now that it is unfashionable to claim high but unearned status on account of one's ancestry and forebears. Whereas it used to be common, in clinical genetics and genetic counselling, to

Angus Clarke

ClarkeAJ@cardiff.ac.uk

1 Institute of Medical Genetics, Cardiff University, Cardiff, UK record a person's "pedigree", one would now generally take their "family history" instead.

Use of the word "mating" in the human context might cause offence if it is seen as being disrespectful to individuals and families or if someone denies that we humans are animal. It is a word that applies equally to all animals and to us humans because we are animals. It is shorn of all social and community context and refers in a very objective and dispassionate manner to the act of sexual intercourse without any of the softening influence of love, family, respect and community that makes marriage and long-term partnership very different from a one-night stand. It is a hard, cold word to apply to humans but would usually only be applied to us within the discourse of human biology and population genetics. The word "mating" has its uses but not in a clinical setting, and it would not usually be applied within the field of genetic counselling.

"Inbreeding" is perhaps the most sensitive of the three words singled out by Small et al., and is addressed by them more fully than the other examples. This is likely to be because a substantial part of the community in Bradford practices customary consanguineous marriage and could see the findings of Clark et al. (2019) as support for those opposed to consanguinity. It would be most unfortunate if a community felt itself as so under threat that it might withdraw from research looking into the causes of important medical problems. Dialogue and understanding between communities is vital, and this will require mutual respect and the sensitive use of technical terminology and of language in general.

The wider issues around consanguinity are discussed in both the editorial by Schmidtke and Cornel (2020) and in the letter by Small et al. (2020) and will not be discussed here except to comment on the term "inbreeding". This is commonly used as a derogatory term in Britain, and needs to be avoided in conversation with families. However, families 
presenting to genetics services will need to be asked about the possibility of consanguinity when their family history is being discussed and recorded. The important points are (i) to ask all patients, whose family histories are being recorded, whether they or their parents could be related to each other by blood, and not to ask only some thought on the basis of appearances and superficial judgements to be more likely to practise consanguinity, and (ii) to enquire about the possibility of consanguinity in a matter-of-fact way and with an open, empathic and non-judgemental manner. It is clear that some health professionals have not been doing this, and have made judgements about - and shown frank hostility towards - the practice of consanguineous marriage. Such professionals need to understand this practice and its role in community life for large groups of humankind; they must also learn to recognize how the nuanced use of language can reveal a lot about their own system of values and beliefs and why their behaviour needs to change. The roots of the hostility to consanguinity run deep, tapping into at least three murky streams of xenophobia, the incest taboo and the cost-saving line of argument justifying negative eugenics (known in the past in Germany as "Race Hygiene"), and is sometimes exploited by politicians who can pick on unfamiliar social customs as an easy target in times of social turmoil. Some of the ideas around customary consanguinity are discussed in the volume that came from an interdisciplinary meeting held in 1994 (Clarke and Parsons 1997).

There are other words used within genetics, whose use can cause offence. These include words for cognitive impairment and words used to name genes and genetic conditions. In relation to cognitive impairment, there has been a cycling of words that are initially used in a neutral, technical sense but which then enter popular use as terms of abuse and which become associated with the stigmatization of those about whom the words are used. The words "moron", "imbecile" and "idiot" have all been used in the past by psychologists, teachers and other professionals as neutral, technical terms to describe persons with varying degrees of cognitive impairment. They are no longer regarded as acceptable terms because of their popular connotations and their use to enact stigmatization. Such recycling of the terms used to describe people with learning difficulties means that any technical vocabulary will have to mutate over time to keep ahead of the terms of abuse. A neutral, descriptive vocabulary of the patterns and degrees of cognitive impairment is clearly necessary for those who assess and support children with special educational needs and it is difficult to see what can be done but to use new terms as the previously established ones become unacceptable through being adopted inappropriately into popular speech.

While words that describe cognitive impairment can be used deliberately to cause offence, another set of problems accompanies the words used to describe the unusual physical features that are found in many disorders of genetic aetiology.
Merely looking different will generate the person's sense of difference from other people, in stature, features or movement. This can trigger ridicule and bring great distress and anguish. However, the words used by clinicians to describe such features can accentuate this sense of difference, becoming terms of abuse and laying them open to further stigmatization. The medical terminology may sometimes be simplified or corrupted when it is used in abuse but is sometime used unchanged. Examples include: dwarf, deformed, spastic, Funny Looking Kid (FLK), "looks different", syndromic. The experiences of people victimized for their physical features are commonly shared within family support groups and have received some attention by social scientists and clinicians, as with neurofibromatosis type 1 , osteogenesis imperfects, achondroplasia, Marfan syndrome and hypohidrotic ectodermal dysplasia (Ablon 1996 and 2002; Peters et al. 2005; Clarke 2013 and 2016). As clinicians, we must acknowledge the sustained stigmatization experienced by many of our patients and their families and take care that our use of terminology in the description of such conditions does not add to their distress.

The naming of genetic conditions raises a number of additional problems. Simply giving a label to a patient's condition, perhaps neurodevelopmental problems in a child, can be experienced as an emotional blow, perhaps more so when it is identified as also being genetic because that interacts with questions of guilt and blame. Being told you have a "syndrome", or that your child has one, can be experienced as an added blow because that word can itself be regarded as derogatory, whether or not the condition is thought to be inherited. Then the syndrome name may itself be a cause of added distress, adding insult to the injury already caused by the condition itself. Being told that your child has DEFECT syndrome, CATCH-22 syndrome or CRASH syndrome (three of the worst examples) is harsher than being tagged or labelled with an eponym or a meaningless string of letters and numbers. These three syndromes are conditions where practitioners have named a syndrome on the basis of a memorable acronym, while oblivious to the impact of this cleverness on the lives of people with the diagnosis (Schrander-Stumpel 1998). Down syndrome is an example where the insult "Mongol" may be seen as derogatory to both those affected by trisomy 21 and to the peoples of Mongolia and their descendants. Another condition where offence may be caused is the Kabuki syndrome, where both the patients and the Kabuki actors may regard this application of a name to a condition as being inappropriate (Kajii and Niikawa 1999).

Some particular syndrome names may have very specific consequences. Being told that you have LEOPARD syndrome could make you much more aware - and more self-conscious of your lentigines. Being told that your child has the "cri du chat" syndrome, sometimes a very severe condition, can alter the parents' experience of their child's condition. Instead of 
accepting their child's cry, hearing it can trigger the full distress resulting from the diagnosis.

Those are examples where the name of the condition rubs salt in the wound. Another but different instance is where the eponym attached to the disorder has gained this prominence for wholly inappropriate reasons. Harper (1997) tells the story of Hallervordern and Spatz, whose names were first attached to, and then removed from, a rare neurodegenerative disorder now known as neurodegeneration with brain iron accumulation 1, or pantothenate kinase-associated neurodegeneration. Hallervordern cooperated with the Nazi programme of race hygiene, involving the euthanasia (murder) of the feeble-minded, and his research career flourished as a result. He helped to select the children to be killed so that he could then dissect their brains. Although he had advanced knowledge about this condition, once his complicity in the murder of patients became widely known it was regarded as too repugnant for his name to be honoured in this way so his name, and that of his institute director, Spatz, were replaced by less offensive, more "scientific" terms.

This account is an expansion of the discussion called for and commenced by Small et al. (2020). It will be important for this debate to continue as language changes over time and sometimes quite rapidly, especially in the era of social media. As a result, words that would be regarded as detached and objective one year may cause offence or distress the next, and become familiar terms of abuse and insult on the street the year after that. We need to be nimble and sensitive to avoid causing problems and we can do this by close attention to words and how they are used.

\section{References}

Ablon J (1996) Gender response to Neurofibromatosis 1. Soc Sci Med 42(1):99-109

Ablon J (2002) The nature of stigma and medical conditions. Epilepsy \& Behaviour 3:S2-S9

Clark DW, Okada Y, Moore KHS, Mason D, Pirastu N, et al. 2019. Associations of autozygosity with a broad range of human phenotypes. Nature Communications. doi.org/10.1038/s41467-019-12283-6

Clarke A (2013) Stigma, self-esteem and reproduction: talking with men about life with Hypohidrotic ectodermal dysplasia. Sociology 47(5): 975-993

Clarke A (2016) Anticipated stigma and blameless guilt: Mothers' evaluation of life with the sex-linked disorder, hypohidrotic ectodermal dysplasia (XHED). Soc Sci \& Med 158:141-148

Clarke A, Parsons EP (eds) (1997) Culture, kinship and genes. Macmillan, Basingstoke

Harper PS (1997) 'The naming of genetic syndromes and unethical activities. The case of Hallervordern and Spatz', chapter 16 (pp 221225), in genetics, society and clinical practice Harper P and Clarke AJ, Oxford, bios scientific publishers. Based in part on: Harper PS.1996. Naming of syndromes and unethical activities: the case of Hallervorden and Spatz. Lancet 348(9036):1224-1225

Kajii T, Niikawa N (1999) Reply to letter to the editor by SchranderStumpel-“What's in a name?". Am J Med Genet 83:212

Peters KF, Apse KA, Blackford A, McHugh B, Michaelic D, Biesecker B (2005) Living with Marfan syndrome: coping with stigma. Genetics in Medicine 68(1):6-14

Schmidtke J, Cornel MC (2020) Contentious ethical issues in community genetics: let's talk about them. J Comm Genet 11:5-6

Schrander-Stumpel CTRM (1998) What's in a name? Am J Med Genet 79:228

Small N, Mason D, Wright J (2020) Letter to the editor: time to update the language of genetics from the nineteenth to the twenty-first century: a response to Schmidtke and Cornel. J Community Genet. https:// doi.org/10.1007/s12687-020-00467-3

Publisher's note Springer Nature remains neutral with regard to jurisdictional claims in published maps and institutional affiliations. 